10.1590/S1414-40772018000300014

Este é um artigo publicado em acesso aberto sob uma licença Creative Commons

https://creativecommons.org/licenses/by-nc/4.0/

\title{
Modernidade em (des) encontro: a educação entre expressivismo e objetividade
}

\author{
"Ousarei expor aqui a maior, mais importante, a mais útil regra de \\ toda a educação? Não se trata de ganhar tempo, mas de perdê-lo"
}

(ROUSSEAU, 2014, p. 96).

\author{
Amarildo Luiz Trevisan ${ }^{1}$ \\ Geraldo Antonio da Rosa ${ }^{2}$
}

Resumo: Este artigo procura esclarecer certos conflitos em que incorrem as Teorias da Educação e a formação de professores seguindo os preceitos do reconhecimento. Para isso, parte da divisão proposta por Charles Taylor em seu monumental escrito "Hegel” (1975), quando denota a existência de duas forças contrárias presentes no coração da modernidade: o espírito do Romantismo, por um lado, e o da Ilustração ou do Iluminismo, por outro. A partir da correlação dessas ideias com as filosofias de Rousseau e Kant, procurou-se responder as seguintes perguntas: “Como refletir a Educação para além dos panópticos do sistema, próprios das políticas públicas de avaliação hoje hegemônicas globalmente?” Ou então, “Como desenvolver a resistência a políticas equivocadas sem cair nos riscos do romantismo?" Dessa forma, procurou-se articular a consideração à expressividade com a objetividade das normas e procedimentos no campo das pesquisas acadêmicas, bem como na melhoria das campanhas educativas de mudança da mentalidade social.

Palavras-chave: Modernidade. Expressivismo. Objetividade. Teorias da educação. Formação de professores.

\section{Modern (mis)encounters: education between expressivism and objectivity}

Abstract: The article seeks to clarify certain conflicts in which theories of education and teacher formation incur, following the precepts of recognition. For that purpose, having as starting point the division proposed by Charles Taylor in his monumental "Hegel" (1975), when he denotes the existence of two opposing forces present in the heart of modernity: the Romantic spirit, on one side, and that of Illustration, or Illuminist, on the other. From the correlation of these ideas with the philosophies of Rousseau and Kant, the article proposes a rethinking of the presence of expressivism, or romanticism, in education, by asking: "How do we reflect on education beyond the system's panoptic, natural to the hegemonic today on a global level - public policies' evaluation systems? Or, "how to develop resistance to equivocous policies while avoiding the pitfalls of romanticism?" In this manner, an articulation is sought, that of considering expressivity with the objectivity of norms and procedures in the field of academic research, as well as the rethinking of its presence in the improvement of results of educational campaigns for the change of social mindset

Key words: Modernity. Expressivism. Objectivity. Theories of education. Teacher formation. 


\section{Considerações iniciais}

O trabalho pretende estabelecer algumas conexões entre Expressivismo e Objetividade na Educação sob os códigos hegelianos da teoria do reconhecimento do outro. O texto é resultado de pesquisa intitulada "Educação pós-Auschwitz: a negatividade (in)superável da formação?”, um projeto voltado sobretudo à discussão da obra de Hegel, sob a ótica de alguns intérpretes contemporâneos, para repensar as dificuldades da formação de professores atualmente. ${ }^{1}$ Para isso, serve-se de algumas reflexões de Charles Taylor extraídas de seu famoso livro "Hegel” (publicado pela Cambridge University Press, em 1975), mais tarde acompanhado de uma versão condensada denominada "Hegel e a sociedade moderna" (1979). Com esses trabalhos, Taylor auxiliou decisivamente a voltar a atenção para o filósofo alemão de Stuttgart no universo anglo-saxão, em especial nos Estados Unidos.

Charles Taylor é contemporâneo de Michel Foucault (1926), Jürgen Habermas (1929), Jacques Derrida (1930) e Richard Rorty (1931), tendo nascido em Montreal, Canadá, em 1931. Como são filósofos da mesma geração, compartilham preocupações comuns do século XX e início do século XXI; uma era que a humanidade foi colocada em xeque e conheceu os limites do chamado "progresso sem fim".

A infância e juventude de Taylor ocorreu durante o conflito de duas culturas no Canadá, a inglesa e a francesa, e o seu desenvolvimento intelectual se deveu muito à instância acadêmica realizada em Londres, Inglaterra, na década de 50. Nesse período, além de realizar cursos da graduação ao doutorado identificado com as humanidades, ajudou a organizar a esquerda através do seu envolvimento com alguns intelectuais, o que culminou na fundação da Revista New Left. Fruto de seu trabalho, surge a sua contribuição pioneira para o renascimento da teoria hegeliana do reconhecimento, através do artigo "A política de reconhecimento", publicado em uma obra coletiva por ele organizada e intitulada de "Multiculturalismo: examinando a política do reconhecimento".

O pensamento de Taylor está, desse modo, diretamente ligado à retomada da filosofia de Hegel na contraposição entre a ontologia do reconhecimento e a ontologia da transformação social, própria do Marxismo. Ele é considerado pela tradição anglo-saxônica como um comunitarista, ou seja, enquanto teórico que defende a importância da comunidade política como espaço definidor de ações ativas, contrário à visão dos liberais que acreditavam em um

${ }^{1}$ O projeto foi aprovado com Bolsa no País/Produtividade em Pesquisa - PQ/CNPq - 2013, no Processo no 303044/2013-6, com tempo de vigência de 01/03/2014 por um período de 36 meses. 
espaço pré-político de autonomia acontextual (HOLMES, 2007, p. 42). Mesmo imerso nesse debate, suas preocupações se aproximam bastante dos teóricos frankfurtianos ao questionar a racionalidade instrumental e administrada e buscar inspirações em Hegel para fazer uma crítica aos desvios da modernidade. A sua hermenêutica de Hegel difere, porém, de leituras que o recebiam como um autor ligado ao universo abstrato, como a famosa tese marxista de que os filósofos até agora somente interpretaram o mundo e, portanto, lido a partir de referenciais externos. Fundamentalmente, Taylor procura fazer uma apreciação de Hegel a partir dele mesmo. Nisso, descobre um autor que pensa os conceitos enquanto encarnados na história, isto é, ligados à concretude dos fatos históricos. Essa inversão permite fazer uma análise a contrapelo, interpretando o próprio Marx vinculado às reivindicações da corrente expressivista.

Nesse sentido, Taylor denota, na filosofia de Hegel, a existência de duas forças de pensamento atuando de forma contrária na modernidade: uma que defende a racionalidade de procedimentos, a disciplina e o controle, características do pensamento Iluminista. E outra força oposta, que pretende desenvolver a expressividade, a espontaneidade e a força interior humanas, e que encontrou guarida especialmente no movimento do Romantismo. Essa fonte esteve aliada ao movimento Sturm und Drang, o qual defendia o primado da expressividade e da subjetividade individual sobre o racionalismo, e que encontrou acolhida em diversos autores. Segundo Taylor,

Es por esto que aquellos pensadores que se mantienen en una tradición romántica o expresivista de cualquier género, discípulos de Rousseau, o de Tocqueville, o de Marx, ya sean socialistas, anarquistas, partidarios de la «democracia participativa», o admiradores de la antigua polis como Hannah Arendt, todos le son extraños a la sociedad occidental moderna (2010, p. 473).

Entretanto, questiona-se até que ponto alguns fenômenos na educação contemporânea podem ser evidenciados nessa perspectiva e se é possível entender os conflitos que perpassam as Teorias da Educação, seguindo os preceitos do reconhecimento. Acreditamos que a retomada do pensamento de Hegel por Taylor, se não é uma solução, representa, ao menos, algumas balizas interessantes para interpretar as posições da educação atual e onde elas se encontram no amplo panorama da modernidade.

Desse modo, em um primeiro momento, pretendemos, com esse trabalho: (a) situar, com alguns detalhes, o diagnóstico hegeliano da modernidade na ótica de Taylor; (b) ilustrar o modo como atuam as duas forças que conduzem a modernidade em disputa, na correlação com as filosofias de Jean-Jaques Rousseau e Immanuel Kant e sua articulação do ponto de vista da proposta hegeliana; (c) apresentar algumas implicações da adesão da Educação, quando se aferra unicamente a um desses procedimentos; (d) e extrair algumas consequências dessas 
reflexões para as Teorias da Educação e a formação de professores na trilha do reconhecimento do outro.

A ideia deste artigo é promover um modo de pensamento que provoque a autorreflexão sobre os rumos que a Educação está seguindo. Não se trata obviamente de uma reconstrução exaustiva do pensamento de Taylor, mas apenas, na medida em que interessa, a partir de uma reflexão sobre os dilemas da modernidade, oferecer uma contribuição para as Teorias da Educação e para uma crítica das políticas educacionais. Por esse caminho, a Educação pode repensar as suas estratégias de articulação no campo das políticas de pesquisas acadêmicas, como voltada ao aparato técnico-científico de produção, transmissão e avaliação do conhecimento. E, também, cabe a ela evidenciar melhor o seu envolvimento com as campanhas de humanização, de mudança de comportamentos e de melhoria dos seus resultados e, portanto, de reforço aos valores da convivência democrática.

\section{Romantismo e Ilustração na luta por reconhecimento}

Atualmente, vivemos um tempo de crise na relação do ser humano com o meio ambiente, de tal sorte que urge uma mudança de concepção na postura instrumental que adotamos com a natureza. São muitos os indícios que demonstram haver a necessidade de repensar a relação de objetivação que mantemos com o nosso meio de existência, na medida em que, em nome da ciência e da tecnologia, a sociedade moderna instituiu um pensamento repressivo do natural, do corpóreo e do dionisíaco no ser humano. Essa situação tem se tornado cada vez mais insustentável, sendo que inúmeros sintomas apontam que o planeta está à beira de um colapso, devido ao desequilíbrio ambiental, ao esgotamento de energias e ao aquecimento global, entre outros fatores, os quais reclamam outra forma de pensar a racionalidade em todos os campos do conhecimento.

Portanto, o pensamento da lucratividade e do domínio sobre o meio ambiente natural, que não deixa espaços para cultivar relações diferenciadas com o seu entorno, é confrontado com protestos de toda ordem, originando movimentos filosóficos e literários, como o do Romantismo ou Expressivismo, que persistem até hoje. Porém, se essa dicotomia está presente atualmente, não eram outros os influxos que alimentavam o pensamento da modernidade? $\mathrm{Na}$ apresentação do seu livro "El espíritu de la Ilustración”, Tzvetan Todorov (2014) relembra o espírito que sustenta a proposta do projeto da modernidade exatamente nessa dimensão:

Las grandes ideas de la Ilustración no tienen su origen en el siglo XVIII: cuando no proceden de la Antigüedad, su rastro se remonta a la Eda Media, el Renacimiento o la época clásica. La ilustración absorbe y articula opiniones que en el pasado estaban en conflicto. [...] La Ilustración es racionalista y empirista a la vez, tan heredera de Descartes como de Locke. Acoge en su seno 
a los antiguos y a los modernos, a los universalistas y a los particularistas. Se apasiona por la historia y por el futuro, por los detalles y por las abstracciones, por la naturaleza y por el arte, por la libertad y por la igualdad. Los ingredientes son antiguos, pelo la mezcla es nueva. Lo importante es que durante la Ilustración las diferentes ideas no sólo armonizan entre sí, sino que también salen de los libros y pasan al mundo real (TODOROV, 2014, p. 9).

Duas características da Ilustração chamam a atenção nessa passagem. Primeiramente, a ideia de que o seu projeto é conciliador das contradições ou diferenças por excelência, ou seja, a modernidade é um tempo de reconciliação ou de reconhecimento fundamentalmente e, em segundo lugar, que essa harmonização provoca a saída do discurso para o campo da prática. No entanto, Taylor, em seu extraordinário livro "Hegel", complementado em seu trabalho posterior "Hegel e a sociedade moderna", procura mostrar o porquê de a modernidade não ter prosperado nesse sentido, ou melhor, o porquê do desviou de sua rota original, sem conseguir encontrar a articulação necessária de seus conflitos.

Em princípio, segundo Taylor, Hegel teria percebido a existência de duas fontes de reflexão opostas atuando na modernidade: a força do Romantismo, que preconiza uma idealização da natureza e acredita ser ela constitutiva do ser humano, e uma corrente que aposta fortemente na sua separação da natureza. Essa última estaria comprometida com o que a Ilustração defende e que avalia o ser humano como uma peça da natureza objetivada e sujeita a controles e monitoramentos constantes. O Romantismo representaria uma reação forte a essa perspectiva, na medida em que o homem é parte do meio natural. Hegel idealizava a experiência da antiga Grécia como lugar onde ocorreu essa perfeita simbiose ou integração dos seres humanos com seu entorno natural. Porém, ao se aproximar de uma interpretação expressivista de Hegel, Taylor recebeu algumas críticas, especialmente por ter confundido o expressivismo da antiguidade grega com o modo moderno (BRIONES; LEYVA, 2010, p. XIII).

Ao ser arrancado dessa condição de prisioneiro da natureza, o distanciamento ocorre com o intuito de incluir o ser humano no processo civilizatório. Entretanto, isso acontece sob o signo ou ao custo da perda do contato com seu lado mais espontâneo e natural. Esse dado está relacionado com a perda daquela ingenuidade natural que caracteriza o indivíduo que vive em estado de perfeita harmonia com o seu entorno. O que resulta um ser conformado à grande máquina do sistema, sujeito a todo tipo de controle e classificação, e compreendido, consequentemente, segundo métodos de quantificação, os quais reprimem seu potencial expressivo, criativo e corpóreo. Produz-se, então, um choque entre esses dois tipos ou modos de pensamento: a oposição da esfera da razão e da moralidade, por um lado, que entra em conflito com a tendência à vida em comunidade e de total comunhão com a natureza, por outro. 
Esse embate não permanece aberto simplesmente na modernidade, segundo a interpretação tayloriana de Hegel, entretanto, houve uma evolução ou adaptação dessas dimensões de pensamento em certo sentido. A ideia de integração do ser humano com a natureza migra para a esfera privada da sociedade, alimentando condutas e pensamentos com ênfase na realização pessoal de indivíduos e grupos. Já o outro modo de pensar, que entende a natureza de maneira objetiva e distanciada, transita para a esfera pública, contornando as exigências de controle de tempo, ordem, postura e disciplina, de acordo com os conhecimentos úteis, criando uma sociedade regida pela ordem social burocrática.

No entanto, a autorrealização pessoal não pode ocorrer no mundo do trabalho, pois esse pertence à esfera pública, que está presa aos requisitos do sistema burocrático que é regida de acordo com a ordem e regramento de condutas. Portanto, conclui Taylor (2005, p. 93): “A sociedade moderna, poderíamos dizer, é romântica em sua vida privada e imaginativa, e utilitária ou instrumentalista em sua vida pública, efetiva.” É importante salientar que essa divisão não é tão nítida quanto parece. Ela serve mais para fins analíticos, uma vez que, conforme veremos mais adiante, no caso da publicidade, periodicamente uma das esferas da vida humana lança mão das demandas de outra para se manter e se perpetuar, atuando de forma unilateral.

Como são vários autores que tratam de ambas tendências, a partir de agora, iremos nos concentrar no tratamento dessa questão a partir da contraposição entre as filosofias de Rousseau e Kant. Mesmo que o primeiro tenha influenciado o segundo, é nítido que o pensamento de um diverge fundamentalmente do outro por conta da sua ótica a respeito da postura com a natureza. ${ }^{2}$

\section{Liberdade racional e unidade expressiva com a natureza}

Kant (1724-1804) preocupou-se em estabelecer regras e procedimentos para entender o conhecimento com fundamentação cognitiva e prática, baseado na separação epistemológica entre sujeito e objeto, que consolidou o isolamento do homem da natureza, enquanto que Rousseau questionou justamente esse distanciamento, a antítese fundamental criada entre a natureza do homem e o desenvolvimento da civilização. Tal questionamento também foi proposto por Herder e chegou até Marx, por isso o desafio da filosofia hegeliana em unir essas duas tendências:

\footnotetext{
${ }^{2}$ Em sua obra "Hegel", Taylor se refere a Kant em 65 oportunidades diferentes, enquanto Rousseau soma 27 vezes, o que demonstra a importância de ambos os autores para a arquitetura do seu pensamento.
} 
Esta gran significación atribuida a Herder lleva a Taylor, además, a comprender la intención del proyecto de Hegel como una gran tentativa por establecer una unidad entre Rousseau, Kant y Herder - esfuerzo que se prolongaría, según Taylor, incluso hasta el propio Marx - y no tanto como un intento por superar la oposición entre la antigüedad y el mundo moderno y, de ese modo, las tensiones y los conflictos del propio mundo moderno (BRIONES; LEYVA, 2010, p. XIV).

O desafio para Hegel é hercúleo, uma vez que implica combinar a liberdade racional e autorregulada do sujeito kantiano com a unidade expressiva com a natureza, conforme defendem Herder, Rousseau e o próprio Marx. Rousseau (1712-1778) dedicou a sua vida intelectual para mostrar o quanto o distanciamento da vontade humana em relação à natureza foi prejudicial e o quanto a vontade deveria fazer falar a natureza. Por isso, ainda de acordo com Taylor (2010, p. 20), tanto Rousseau e Herder, quanto os seus seguidores românticos:

Ellos experimentaron esta visión de las cosas como un destrozo de la unidad de la vida en donde la naturaleza debía ser al fin la inspiración y el motivo que forzara al pensamiento y a la voluntad. No era suficiente que la naturaleza proveyera el mapa para la voluntad, la voz de la naturaleza debía hablar a través de la voluntad.

Disso resulta uma teoria contrária às dicotomias clássicas de corpo e alma, espírito e natureza, que foi legada por Descartes. Diferente de Kant, Rousseau não aceita a separação entre sensibilidade e entendimento, o que fez com que Hegel se aproximasse mais dele do que de Kant, uma vez que, dessa forma, o ser humano estaria mais completo. Nesse sentido, o pensamento de Rousseau, enquanto teórico expressivista auxilia na compreensão da teoria hegeliana como essencialmente antidualista. Sua filosofia é amante não somente da natureza, mas também da liberdade, e foram esses elementos que contribuíram fundamentalmente para a sua incorporação à filosofia hegeliana.

Dentro dessa forma de pensamento, levar ao fim a decisão de todos significa pôr em prática a liberdade humana via vontade geral. Entretanto, para se tomarem decisões em seu nome, não há como admitir instituições representativas. As instituições devem buscar uma participação universal que tome conta da vontade de todos. A partir dessa perspectiva, o Estado deve ser expressão da vontade geral.Por isso Rousseau é considerado o pai das democracias diretas ou participativas, que vão além da ideia de pura representação. Taylor (2010, p. 160) deduz ser por isso que Hegel assim se refere a ele: "En este mundo de libertad absoluta no ha de haber representación, sino volutad conjunta."

Rousseau se antecipa no combate da perspectiva humana concebida a partir da Ilustração, colocando como eixo central a liberdade moral, sendo que Kant assume uma postura mais radical nesse sentido: 
La figura principal en esta revolución de la libertad radical es sin duda Immanuel Kant. Rousseau en muchos sentidos anticipó la idea, pero fue la formulación de Kant, ese gigante entre los filósofos, la que se impuso, entonces y todavía ahora. En un trabajo filosófico tan poderoso y rico en detalle como la filosofía crítica de Kant, el rastreo de cualquier tema singular implica mucha simplificación, pero no es mucha distorsión decir que la reivindicación de esta subjetividad moral radicalmente libre fue una de las principales motivaciones de la filosofía de Kant (TAYLOR, 2010, p. 26).

Desse modo, a vontade do indivíduo não está determinada por uma normativa exterior, nem somente pela busca do interesse individual ou coletivo. É o imperativo categórico que confere autonomia como único princípio de todas as leis morais, de tal forma a ser ele a determinação da livre vontade de forma legislativa e simplesmente universal, pois, sendo máxima, deve ser capaz.

Além da ideia de subjetividade como liberdade radical, outro motivo é fundamental para definir a filosofia kantiana enquanto ligada ao movimento da Ilustração, que buscou a separação do homem da natureza: a distinção entre fenômenos e coisa em si. Eis o que afirma Taylor (2010, p. 101) sobre isso:

\footnotetext{
La brecha epistemológica entre el hombre y la naturaleza se expresa en su forma más conocida con la distinción kantiana entre fenómenos y $<<\operatorname{cosas}$ en sí mismas $>>$. Las últimas eran para siempre y por principio incognoscibles. Hegel dirige una poderosa polémica contra la $<<$ cosa en sí misma >> kantiana. Y el argumento final es éste: ¿cómo puede haber alguna cosa más allá del conocimiento, algo que esté más allá de la mente o del Geist, si el Geist es en última instancia idéntico con toda la realidad?
}

O Iluminismo deixa profundas marcas ao estabelecer a natureza como um conjunto de fatos e, neles, a própria natureza humana de forma objetiva, criando, na visão de Taylor, uma fissura entre a natureza enquanto instrumento e a vontade que atuava nesse plano. Nesse sentido, a nova liberdade é concebida como referencial da autoexpressão, sendo ameaçada por todas as forças contrárias dos mecanismos que a tolhem.

Ao comentar o escrito juvenil hegeliano "Maneiras de tratar cientificamente o direito natural”, Ramos (2011) deixa mais clara a diferença da sua posição em relação a Kant e Rousseau. Nesse trabalho, Hegel caracteriza três modos diferenciados de tratar o direito natural: o empirista de Hobbes, Locke e Rousseau, o formalista de Kant e Fichte, e o modo especulativo, atribuído a si próprio.

O equívoco do modo empírico de conceber o direito natural radica-se no fato de que os indivíduos particulares estão em permanente conflito uns com os outros, não possuindo um vínculo entre si. Para que isso aconteça, é preciso uma força externa e coercitiva, própria do Estado. O Estado em si tem, como pressuposto de suas ações, a arbitrariedade e o consentimento dentro da perspectiva contratualista, uma vez que o papel do contrato é obter que as vontades individuais cheguem a um acordo. 
Assim sendo, as forças exteriores agem para a manutenção da coesão social e, por isso, serão sempre arbitrárias, o que leva Hobbes a assumir um Estado Leviatã todo poderoso, ou então à posição expressivista de Rousseau, que requer uma formatação do Estado como expressão da vontade geral. Já o modo formalista de Ficthe e Kant incorre no mesmo erro ao admitir a ideia da coerção para garantir a unidade, o que supõe relações de exterioridade.

É por isso que, no aspecto referente à participação universal por meio do contrato social, Taylor enfatiza em Rousseau a defesa de uma forma de associação em que o homem possa entrar e obedecer a si próprio e ser tão livre quanto antes. Ele salienta ser a vontade geral e os processos de participação os procedimentos por excelência para a harmonização da sociedade. Com isso, o papel arbitrário do Estado é neutralizado, e as ações daí emanadas irão ao encontro da igualdade fundamental em todos os processos decisórios, buscando o consenso.

A Ilustração, de certa maneira, trilha na direção de um ser humano dentro da concepção utilitarista e, em função disso, Taylor entende Hegel próximo da concepção de Estado que Rousseau propugna em sua obra "Contrato Social", na direção da igualdade de todos perante a lei. O homem se corrompe ao participar da sociedade que caminha de acordo com os preceitos da racionalidade universal própria do objetivismo. Porém, Hegel avança em termos de filosofia política,e não apenas reforça o pensamento contratualista, ao admitir que a proposta de Rousseau, de um Estado sem representação, sem estruturas legislativas, não o tornaria operatório, ou seja, inviabilizaria o seu funcionamento. É preciso criar diferentes funções no Estado:

En otras palabras, para que exista realmente en la historia una comunidad humana política, incluso emanada de una voluntad general ha de encarnarse en algunas instituciones; pero las instituciones implican diferenciación, la interrelación de los hombres que están relacionados de manera diferenciada con el poder (TAYLOR, 2010, p. 160).

Hegel reconhece em Rousseau o ponto de partida baseado na concepção de um homem essencialmente bom em sua natureza e espontaneamente altruísta, porém não compartilha com a ideia de que o estado de natureza também o seja. Na verdade, entende que esse estado representa uma ameaça constante, pois como nele não há qualquer regramento, a vida humana encontra-se permanentemente em risco. É nesse sentido que Hegel afirma, em sua obra "Enciclopédia das ciências filosóficas", o seguinte:

El derecho de la naturaleza es, por tanto, la existencia de la dureza y la supremacía de la fuerza; y un estado de naturaleza es un estado en el que se ejerce violencia y carece de derecho; un estado del que no se puede decir nada más verdadero que hay que salir de él. La sociedad por el contrario es más bien el único estado en el que tiene su efectiva realidad el derecho; lo que certamente hay que limitar y sacrificar es la arbitrariedad y la violencia propios del estado de naturaleza. (HEGEL, 1997, p. 532-533). 
Para se opor aos contratualistas, que defendiam a exterioridade da natureza, Hegel (1997) rompe com a ideia do contrato em troca da ideia de uma "vida ética orgânica". A vida ética seria "a unidade do estado de natureza e da majestade (do Estado)", de tal forma que não há nada de absolutamente exterior à liberdade humana, sendo o Estado expressão da "natureza ética absoluta" (RAMOS, 2011, p. 99). Na exterioridade da natureza, prevalecem relações de dominação e submissão, e essas somente serão superadas com a entrada nas relações de eticidade, em que cada um reconhece o outro como livre e igual. Taylor (2010, p. 26) expressa seu pensamento da seguinte forma: "En lugar de estar disperso entre diversos deseos e inclinaciones el sujeto moralmente libre debe ser capaz de mantenerse integrado en sí mismo por decirlo así, y hacer con su decisión un compromiso total.”

Hegel (1997) tem consciência de que a separação da natureza é um ganho em termos de liberdade racional, no sentido de libertação das imposições da própria natureza, da sociedade, da autoridade do soberano, de Deus ou do destino, e tem consciência de que isso não tem mais volta. O desafio é reconciliar a autonomia racional, oriunda do disciplinamento do seu impulso interior, que o tornou um ser livre, com a unidade representada pelos mesmos poderes acima (TAYLOR, 2005). A sua resposta ao desafio de harmonizar as forças antagônicas sem retorno ao passado é o de que essas dicotomias não são apenas opostas, mas também idênticas ao seu oposto, isto é, quando elas atuam isoladas, acabam se tornando semelhantes pela sua ineficácia. Entretanto, a identidade deve incluir a identidade da diferença, sem que isso implique um retorno à unidade primitiva do bom selvagem. Desde essa perspectiva, essas forças mantêm uma unidade por meio da oposição, o que fortalecerá a ambas e permitirá que alcancem a plena força, ou seja, é o conflito devidamente harmonizado que irá fortalecê-las e não o contrário (TAYLOR, 2005, p. 65).

A seguir, faremos uma incursão pelo campo da Educação, tentando apresentar algumas implicações da sua adesão a esses procedimentos, especialmente no sentido da renúncia dos imperativos românticos em nome dos controles sistêmicos via avaliação educacional no campo da pós-graduação, por exemplo, ou da sua captura por intermédio da indústria cultural.

\section{Força dionisíaca da natureza versus demandas da sociedade utilitária na Educação}

Assim como outras áreas do conhecimento, a Educação Moderna encontra-se dividida internamente entre a contemplação de um espírito romântico, que acredita na relação fraternal do ser humano com a natureza, consigo próprio e com os outros a partir do desenvolvimento das forças psíquicas e interiores humanas, e a perspectiva contrária, que defende o controle pelo 
sistema da compreensão do conhecimento, por intermédio de avaliações e outros procedimentos. Enquanto a última proposta pretende estabelecer disciplinas e regras para o processo pedagógico adequar-se à produtividade vigente, a primeira defende que não há uma bússola para o conhecimento e que o ideal é o próprio indivíduo descobrir as suas próprias regras e buscar a autorrealização. Dessa forma, mesmo sem entender completamente, os sujeitos se orientam por regulamentos que eles mesmos vão criando ao longo do processo de ação, ou se aferram à lógica do saber como bússola, para se guiarem pelos meandros dos acontecimentos.

Questiona-se até que ponto a Educação não está tomada por certo utilitarismo, deixando de lado a tendência oposta do Expressivismo, e como a Educação deve refletir para além dos panópticos do sistema, próprios das políticas públicas de avaliação hoje hegemônicas globalmente, ou melhor, como se deve desenvolver a resistência a essas políticas, sem cair nos riscos do romantismo.

Encontramos rastros dessa primeira tendência moderna nas propostas das "reformas compreensivas" (CARREÑO; COLMENAR; EGIDO; SANZ, 2008), do “construtivismo" e de alguns pensamentos, como a expressão "pensamento sem corrimões", em Hannah Arendt (LUDWIG, 2013), e do conceito de "amorosidade", em Paulo Freire (1998; 2000) que advogam uma natureza humana boa, solidária e avessa a controles externos.

A segunda dimensão da modernidade já está consolidada nas atuais políticas do governo de controle dos sistemas e unidades de ensino, tendo o efeito de regrar e qualificar o processo de produção, transmissão, avaliação do conhecimento e distribuição de recursos. O Estado brasileiro sofre efeito das políticas internacionais inspiradas nos preceitos do Iluminismo, as quais influenciam, de maneira direta, as políticas públicas nos diferentes níveis de ensino. Por isso, essas políticas se articulam no cotidiano dentro de uma racionalidade pautada pelo objetivismo, sendo que a expressão da vontade geral e as demandas emergentes da eticidade não se encontram, por vezes, entre as prioridades do processo educativo. Tal lógica encontrase centrada nos Parâmetros Curriculares, nas Diretrizes para Formação de Professores e nos Projetos Pedagógicos, fazendo com que as instituições não tenham clareza da sua real função.

Podemos entender aqui o porquê dessas políticas não conseguirem, por vezes, se adequar ou expressar a singularidade dos diferentes contextos. E a luta que travam os indivíduos, os grupos, ou mesmo as instituições situadas em entornos desfavoráveis que acabam não contagiando o conjunto da sociedade com as reivindicações da Educação. Existem posições de resistência a essas políticas, que defendem exatamente a relatividade, a subjetividade de noções e princípios, a recepção de contextos diferenciados como pedra de toque decisivo para 
que tais ações tenham mais aderência à realidade e, assim, maior produtividade. Entretanto, como a resistência a políticas equivocada renunciam a pensar a totalidade ou a generalidade da adoção de regras, têm-se revelado ilhadas em um idealismo romântico e atuado sem efetividade prática, uma vez que acabam limitando-se a contextos próprios ou muito específicos de atuação.

No que segue, efetuaremos uma relação dessas duas forças da modernidade com o envolvimento da Educação em dois campos de atuação diferentes: no campo de avaliação da produção do conhecimento nas universidades e na melhoria da convivência democrática através das campanhas educativas de mudança da mentalidade social.

\section{A exclusão do Romantismo nas políticas de avaliação da Educação Superior}

A visão de expressividade da vontade geral, incorporada pela filosofia hegeliana a partir de Rousseau, permite observar certa contraposição ao posicionamento Iluminista, uma vez que, por meio dos processos de normatização, da individualização e do utilitarismo, existe, de forma escamoteada, a perspectiva de fazer valer essa vontade através do discurso democrático e de forma direta ou mesmo alternativa de participação. Entretanto, o caráter normativo, pautado dentro da visão da Ilustração, atende somente a uma parcela dos interesses e não às aspirações mais amplas da coletividade. O processo de regulação da sociedade acolhe uma pretensa vontade geral que é a aspiração de uma minoria em nome da maioria, sendo que grande parte do contingente populacional encontra-se alijado dos processos decisórios.

O resultado da exclusão dos valores românticos expresso na política de desvalorização da expressão da vontade geral e de valores universais em nome da meritocracia levou a um impasse no progresso da ciência, que é descrito por Todorov (2014) do seguinte modo:

\footnotetext{
Desde muchos puntos de vista nuestro tiempo ha pasado a ser el del olvido de los fines y el de la sacralización de los medios. El ejemplo más claro de esta radicalización nos lo ofrece quizá el desarrollo de la ciencia. No se incentivará y se financiará el trabajo científico porque sirva directa o indirectamente a finalidades especificamente humanas - la felicidad, la emancipación o la paz -, sino porque prueba el virtuosismo del estudioso (p. 96).
}

Sendo assim, os valores ligados ao Expressivismo tornaram-se tão dissociados dos processos de avaliação da pesquisa e da pós-graduação que a Educação não tem poder para reuni-lo, ou melhor, ela não tem a força de coesão social capaz desse esforço prometeico, embora possa oferecer a sua contribuição crítica. Também, não compete às estratégias de atuação da Educação, para ter o efeito desejado, simplesmente opor uma dimensão a outra, como se fosse suficiente fazer chocar, por exemplo, a expressividade do processo formativo contra a autonomia do eu e o regramento de condutas. Desse ponto de vista, o que lhe incumbe 
é redefinir as suas estratégias de intervenção e oposição, redirecionando demandas de maneira interna aos próprios processos.

Na realidade, a exclusão dos valores ligados ao Romantismo na pesquisa esteve muito mais a serviço do sufoco à autonomia, à criatividade e à própria autoexpressão da universidade, dado que, segundo Chauí (2003, p. 7), "A heteronomia da universidade autônoma é visível a olho nu: o aumento insano de horas/aula, a diminuição do tempo para mestrados e doutorados, a avaliação pela quantidade de publicações, colóquios e congressos, a multiplicação de comissões e relatórios etc."

Deve haver êxito na Educação, mas não podemos perder de vista que todo esse afã avaliativo das políticas em curso tem se revelado, na verdade, bastante inócuo. Poderíamos nos perguntar, por exemplo, sobre o porquê de o Brasil não ter obtido, até o momento, a conquista de nenhum prêmio Nobel e de não ter nenhuma universidade situada entre as 100 melhores do mundo nos rankings internacionais. Chauí (2003, p. 9) questiona sobre o que se produziu de novo em um determinado campo do conhecimento, diante de tanto aparato de controle:

Penso que se poderia acrescentar aqui: as cifras sobre a quantidade e a velocidade dos conhecimentos, as cifras provenientes da publicação de artigos nos quais são apresentadas descobertas científicas, pode levar-nos ainda auma outra reflexão, qual seja: a quantidade de descobertas implicou uma mudança na definição de uma ciência?

Não estamos defendendo, com isso, o fim da concorrência ou da competição simplesmente; a cultura já está consolidada e incentivada pelos próprios órgãos oficiais de avaliação, ou melhor, os resultados das avaliações e ranqueamentos levam a isso, e a a maneira como são utilizados os resultados dá margem para a apropriação competitiva. De outro modo, seria o caso talvez de demonstrar o quanto esse tipo de estratégia é falho ao não se aliar à expressividade do ser humano, às forças interiores do desenvolvimento psíquico e espiritual, para se concentrar apenas em avaliações "externas".

O reconhecimento da dimensão expressivista ou romântica na pesquisa poderia levar ao incentivo do gosto da investigação e da descoberta do novo como mote principal dos seus procedimentos. Isso despertaria o interesse do estudante pela ciência e cultura, e não exatamente o controle do quanto de métrica se aprendeu ou se deixou de aprender via processo transmissivo, exclusivamente.

A seguir, faremos uma análise das campanhas de humanização, de mudança de comportamentos e de melhoria dos seus resultados no campo da convivência democrática pela ótica da interrelação entre as duas forças opostas da modernidade, segundo a avaliação tayloriana de Hegel. 


\section{A captura do ideal romântico pela exploração da indústria cultural}

A produção e consumo do tabagismo no Brasil e no mundo são assustadores e revelam uma verdadeira catástrofe em curso. Segundo dados apresentados por Giacomini Filho e Caprino (2006), o Brasil é o segundo maior país produtor e o maior exportador de fumo do mundo. Uma pesquisa inédita do Ministério da Saúde e do Instituto Brasileiro de Geografia e Estatística (IBGE), realizada em 2014, revela que o índice de pessoas que consomem cigarros e outros produtos derivados do tabaco é $20,5 \%$ menor que o registrado cinco anos atrás (PORTAL DA SAÚDE, 2014). Ainda há muito que fazer nesse campo, pois $14,7 \%$ dos entrevistados nessa pesquisa disseram que fumam atualmente e ainda contabilizamos cerca de 200 mil óbitos por ano relacionados ao tabagismo. Além disso, a Organização Mundial da Saúde (OMS) estima que um terço da população mundial adulta, cerca de 2 bilhões de pessoas, sejam fumantes, sendo essa a principal causa de morte evitável em todo o mundo (PORTAL BRASIL, 2014).

As empresas produtoras de tabaco lançam mão de estratégias para a manutenção do consumo do cigarro em alta através das propagandas, que lembram reivindicações próprias do Expressivismo ou do Romantismo. Já as campanhas antitabagistas expõem órgãos de pessoas afetadas em cartazes ou nas carteiras de cigarro, com o intuito de criar consciência dos malefícios do cigarro para a saúde. Ao dissertar sobre a predominância das estruturas do racionalismo sobre os imperativos românticos da vida privada, Taylor acaba tocando indiretamente nessa questão, quando assevera:

Contudo, a predominância cotidiana dessas estruturas coletivas sobre o romantismo privado é evidente na exploração das imagens românticas de realização para manter as engrenagens da indústria funcionando, por exemplo em grande parte da propaganda contemporânea (2005, p. 93-94).

Em função da cultura que se instaurou na sociedade, influenciada pela indústria do consumo, a publicidade envolve a relação com as imagens de apelos sedutores e românticos. Giacomini Filho e Caprino (2006, p. 4) afirmam que, no século XX, houve, primeiramente, a utilização de "figuras de mulheres nuas ou sedutoras"; a partir dos anos 50, "a virilidade masculina" entrou em cartaz e, mais tarde, "a ideia de glamour aliada ao cinema", como estratégia das indústrias para o incentivo ao vício do cigarro através da propaganda.

Os valores do Romantismo são utilizados como forma de escamotear a manipulação das empresas para vender um produto extremamente prejudicial à saúde. Não é por acaso que as propagandas publicitárias proliferaram com a utilização em larga escala dos apelos da estética, 
porém, o seu enfrentamento é realizado pela contra publicidade de cigarros através do emprego de armas da normatização das condutas, que lançam mão da autonomia do eu para que o indivíduo tenha vida longa e saudável.

Isso significa querer diminuir o vício do tabaco contrapondo-se à estética, baseado no preceito do que representa o ato de deixar de fumar em termos de ganhos para a saúde. Ou seja, as campanhas de combate ao consumo do tabaco estão trabalhando com os códigos de uma dimensão contrária a outra (a Objetividade contra o Expressivismo). O que ocorre é que o indivíduo consumidor não se reconhece nas imagens que aparecem nas propagandas antifumo: "Expurgado de atividades relacionais, o outro que é retratado em sua dramática condição enfermiça nos maços de cigarro não lhe diz respeito.” (SILVEIRA; PIENIZ; FRAGA, 2010, p. 112).

Ao expor a experiência do Canadá no combate ao consumo do tabaco, que passou pelos mesmos processos de exposição dos órgãos de pessoas danificadas nas carteiras de cigarro, Sontag (2014) chega à conclusão semelhante. A autora diz que um estudo apontou que a probabilidade de uma pessoa deixar de fumar, ao contemplar essas imagens nas carteiras, era de 65 vezes mais do que se constasse apenas uma advertência escrita sobre os seus efeitos nefastos aos fumantes. Porém, sua crítica a esse expediente é que a comoção pela visão daquelas imagens horrendas pode desaparecer com o tempo, pois as pessoas possuem meios que as protegem de contemplar imagens desagradáveis, simplesmente não as mirando mais: "Esto parece normal, ES decir, adaptación. Al igual que se puede estar habituado al horror de la vida real, es posible habituarse al horror de unas imágenes determinadas" (SONTAG, 2014, p. 73).

Há a necessidade do envolvimento da Educação com as campanhas de prevenção a mudanças de comportamento, no sentido da melhoria dos resultados para baixar o seu consumo, o que poderia impactar no avanço dos valores ligados à convivência democrática. Assim sendo, o vício de cigarro não poderia ser melhor combatido com os apelos do próprio campo da estética? Ou, se as campanhas alertassem para o quanto é feio, maléfico ou desagradável fumar, que não há glamour nenhum em deixar o ar poluído, entre outras consequências nefastas para a saúde, não seriam mais eficazes em seus objetivos? "Nesse sentido, o hábito de fumar teria ingredientes lúdicos e simbólicos poderosos, que, se usados no sentido da dissuasão, poderiam redundar em efeitos mais positivos nas campanhas antitabagistas" (GIACOMINI FILHO; CAPRINO, 2006, p. 5).

Percebemos, desse modo, a distinção e também a identidade entre essas duas forças aparentemente opostas, pois, assim como elas estão em conflito, encontram-se identificadas na 
sua impotência, enquanto agem de forma isolada uma da outra. E isso implica na necessidade de reconhecimento e de reconfiguração na relação entre ambas.

\section{Conclusão}

Esse artigo procurou evidenciar os aparatos cognitivos que estão por trás de duas forças de pensamento da modernidade, impulsionando-as. Dissertou-se sobre: a) a ambivalência contida no coração do discurso moderno, entre uma educação regrada e metódica (Kant), ou expressivista e romântica (Rousseau); e b) a tentativa de Hegel, mediante a teoria do reconhecimento, de promover a síntese. Sabe-se que essa é uma apropriação um tanto restrita do pensamento de Taylor, que exige investigações posteriores para a sua devida complementação.

Nessa ótica, a humanidade está diante de dois posicionamentos: de um lado, o Expressivismo, que pauta o desenvolvimento humano com a aproximação da natureza, ou seja, apelando para o poder interno aos sujeitos; e, de outro, o Objetivismo que se caracteriza por buscar a normatização das ações humanas. Taylor propõe uma integração desses posicionamentos a partir dos parâmetros do pensamento hegeliano, que encontraria apoio, além de Rousseau e Kant, também em Herder, podendo chegar até Marx, com o objetivo de superar as oposições e conflitos da modernidade. Hegel é o pai da Teoria do Reconhecimento, porque percebeu a presença dessas duas forças na modernidade (Romantismo e Ilustração) e propôs uma saída, considerada por Taylor (2005) importante até hoje, como podemos ver a seguir:

\footnotetext{
Mas a tensão em nossa civilização hoje provém do fato de que não podemos e não queremos abandonar totalmente a tendência racional e tecnológica de nossa sociedade, derivada do Iluminismo, embora sintamos constantemente o apelo das aspirações à autonomia radical e à unidade expressiva. Um pensador que tentou combinar as três coisas tem algo a nos dizer que os meros protagonistas da rebelião romântica não têm (p. 94-95).
}

Entretanto, cabe questionar: a) o que resulta para a Educação atualmente se entendermos os conflitos que a perpassa por esses processos; b) que ser humano está sendo formado e baseado em que ideal queremos formar, se o que buscamos fundamentalmente é nos distanciar cada vez mais da expressão da natureza; c) como recuperar essas demandas como um dos alicerces importantes do próprio ato de educar?

A partir dessas reflexões, resulta para a Educação uma demanda que tenta dar conta das suas insuficiências, enquanto pensadas exclusivamente. No instante em que prevalece somente a oposição entre essas duas formas de pensar, não há reconhecimento, ainda não existe uma verdadeira humanidade, porque ora o ser humano é dominado pela força da natureza, ora pela 
força da racionalidade. Somente se tem a humanidade toda, quando ocorre o passo do reconhecimento de uma pela outra, quando se dá importância à percepção emocional, subjetiva ou privada e, ao mesmo tempo, objetiva e social.

A formação de professores aponta claramente para a situação de conflito, sobretudo quando aposta unicamente na relação do professor com o estudante como horizonte exclusivo de possibilidade, para que haja uma melhoria dos problemas que a educação enfrenta. Sem dúvida, se os mestres guiam suas condutas inspiradas no horizonte de estima e consideração ao educando, eles tendem a obter mais êxito em sua prática diária, embora isso, por si só, não seja o suficiente.

É preciso ir além das reivindicações puras e simples dos métodos ativos de construção do conhecimento pelo aluno, caso contrário, a progressão continuada, o construtivismo, as reformas compreensivas e outras fórmulas de retirada dos controles na educação teriam obtido pleno êxito. E mesmo havendo a necessidade constante do questionamento a regras de disciplinas e de autoridade das normas, não é preciso aderir ao lado oposto simplesmente, assim como, para favorecer um modelo de ensino, não é necessário desacreditar totalmente o outro.

Necessitamos também interrogar os fenômenos de adesão à prática imediata e às avaliações sistemáticas de ranqueamento das instituições de ensino, como se pudéssemos produzir conhecimento em série sem adesão aos entornos desfavoráveis e a sua transformação. Educação é parte de um sistema mais amplo, carente de mudanças interiores e exteriores e, por isso, ela precisa questionar as campanhas de modificação da mentalidade social, como as de prevenção de morte no trânsito, de consumo de bebidas alcoólicas ou cigarros, entre outras, uma vez que isso lhe diz respeito direta e indiretamente. Sem essa contribuição, tais campanhas continuariam operando no nível da guerra de marketing sem fim, que não provoca uma mobilização ou movimento mais amplo da sociedade, que poderia lhe oferecer sustentação e modificação.

Os panópticos do sistema, próprios dos modelos de controle e avaliação da qualidade dos processos de ensino deveriam, nessa perspectiva, saber incorporar a sensibilidade aos diferentes contextos, a relatividade da recepção cultural e o incentivo à atividade e à criatividade dos estudantes. Seria mais produtivo para a Educação, nesse caso, um apego ao idealismo romântico, seja que nome ele tiver - a ideia da transformação social ou do indivíduo (auto)cultivado, por exemplo, posto que tais dispositivos potencializariam o desenvolvimento de sistemas, instituições e indivíduos, de dentro para fora, e não somente de fora para dentro, como sugerem as "avaliações externas". 
O reconhecimento do outro é um modus operandi muito importante para a Educação, que lhe auxilia provocando mudanças externas e internas concomitantemente. Embora não seja uma fórmula simples, porém, algo muito exigente, o reconhecimento funciona no nível do entendimento sobre a base da busca, da aceitação e do reconhecimento do direito à diferença. Portanto, o efeito educativo sobre o comportamento de indivíduos ou grupos depende de um ato racional, porém combinado com a influência do meio ambiente natural.

\section{Referências}

BRIONES, Pablo Lazo; LEYVA, Gustavo. Prólogo. In: TAYLOR, Charles. Hegel. Rubí (Barcelona): Anthropos Editorial, 2010.

CARREÑO, Miryam; COLMENAR, Carmen; EGIDO, Imaculada; SANZ, Florentino. Teorías e instituciones contemporáneas de educación. Madrid: Sintesis Educación, 2008.

CHAUÍ, Marilena. A universidade pública sobnova perspectiva. Rev.Bras. Educ., Rio de Janeiro, n. 24, p. 5-15, 2003.

FREIRE, Paulo. Pedagogia da autonomia: saberes necessários à prática educativa. 7. ed. São Paulo: Paz e Terra, 1998.

FREIRE, Paulo. Pedagogia da indignação: cartas pedagógicas e outros escritos. São Paulo: UNESP, 2000.

GIACOMINI FILHO, Gino; CAPRINO, Mônica Pegurer. A propaganda de cigarro: eterno conflito entre público e privado. In: CONGRESSO MULTIDISCIPLINAR DE COMUNICAÇÃO PARA O DESENVOLVIMENTO REGIONAL, 2006, São Bernardo do Campo. Anais... São Bernardo do Campo: Universidade Metodista de São Paulo, 2006. Disponível em: <http://encipecom.metodista.br/mediawiki/images/e/ef/GT1-_COMSAuDE_03-_A_propaganda-_Monica.pdf>. Acesso em: 24 jan. 2015.

HEGEL, Georg Wilhelm Friedrich. Enciclopedia de las ciencias filosóficas. Madrid: Alianza Editorial, 1997.

HOLMES, Pablo. A modernidade como dilema entre a eticidade e a moralidade: a crítica de Charles Taylor à teoria do discurso. Controvérsia, São Leopoldo, v. 3, n. 2, p. 42-52, jul./dez. 2007.

LUDWIG, Cristiane. Educar sem corrimões? A formação em tempos de ruptura com a tradição. Inter-ação, Goiânia, v. 38, p. 519-535, 2013.

PORTAL Brasil. Cigarro mata mais de 5 milhões de pessoas, segundo OMS. 2014. Disponível em: <http://www.brasil.gov.br/saude/2014/08/cigarro-mata-mais-de-5-milhoes-depessoas-segundo-oms >. Acesso em: 02 fev. 2015.

PORTAL da Saúde. Número de fumantes no Brasil cai $20,5 \%$ em cinco anos. 2014. Disponível em: <http://portalsaude.saude.gov.br/index.php/cidadao/principal/agenciasaude/15973-numero-de-fumantes-no-brasil-cai-20-5-em-cinco-anos>. Acesso em: 2 fev. 2015.

RAMOS, Cesar Augusto. Hegel e a crítica ao estado de natureza do jusnaturalismo moderno. Kriterion, Belo Horizonte, n. 123, p. 89-104, jun. 2011. 
ROUSSEAU, J. J. Emílio, ou da Educação. 4. ed. São Paulo: Martins Fontes, 2014.

SILVEIRA, Ada C. M.; PIENIZ, Mônica; FRAGA, Pauline N. Lugares de captura: reificação e consumo na indústria cultural. Comunicação, mídia e consumo, São Paulo, v. 7, n. 18, p. 105-124, mar. 2010.

SONTAG, Susan. Ante el dolor de los demás. 3. ed. Barcelona: Liberdúplex, 2014.

TAYLOR, C. (Org.). Hegel. Rubí (Barcelona): Anthropos Editorial, 2010.

TAYLOR, C. (Org.). Hegel e a sociedade moderna. São Paulo: Loyola, 2005.

TODOROV, Tzvetan. El espíritu de la ilustración. Barcelona: Galaxia Gutenberg, 2014.

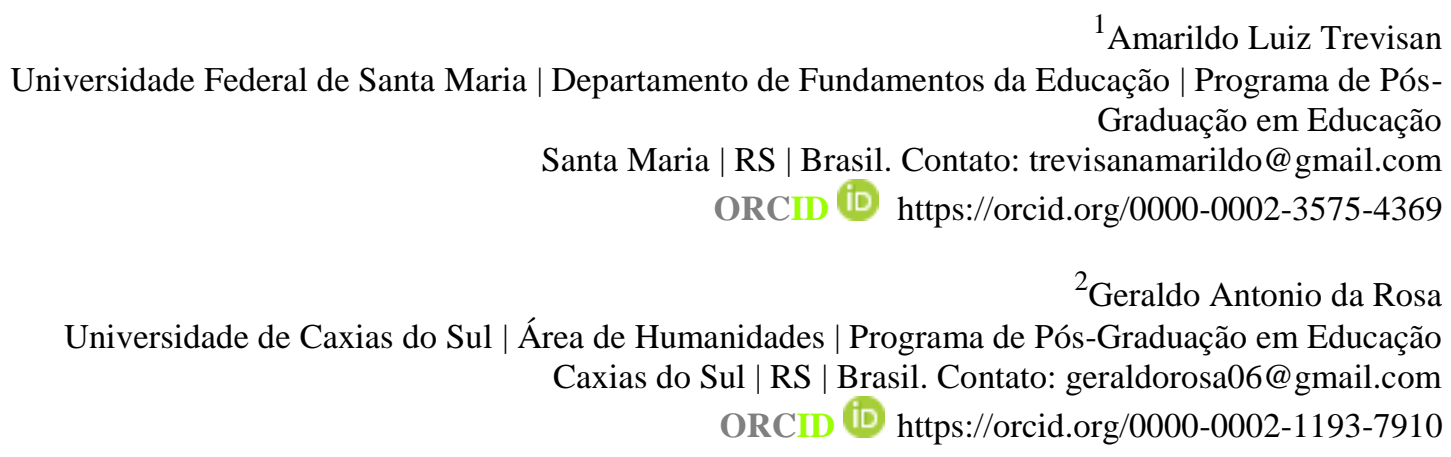

Artigo recebido em 6 de abril de 2016 e aprovado em 19 de setembro de 2016 